\title{
Produtividade de duas cultivares de mamona submetidas a diferentes lâminas de irrigação suplementar
}

\author{
Guilherme A. Biscaro', Marcos A. B. Vaz ${ }^{2}$, Graziane M. Giacon ${ }^{3}$, \\ Eder P. Gomes ${ }^{4}$, Silvana B. da Silva ${ }^{3}$ \& Anamari V. de A. Motomiya ${ }^{4}$
}

\begin{abstract}
RESUMO
Objetivou-se com este trabalho avaliar a produtividade de grãos, os componentes da produção e a quantidade de óleo produzida por duas cultivares de mamona, irrigadas por gotejamento e submetidas a diferentes lâminas de água. O experimento foi conduzido no ano agrícola de 2009, em um Latossolo Vermelho distroférrico, textura argilosa, em área experimental no município de Dourados, MS. O delineamento experimental foi em blocos casualizados, no esquema fatorial, com cinco lâminas de água $(0,25,50,100$ e $150 \%$ da evapotranspiração para irrigação localizada) em duas cultivares de mamona (IAC 2028 e IAC 80), com quatro repetições. O turno de rega foi predeterminado em duas irrigações semanais, excetuando-se os dias em que ocorreu precipitação pluviométrica. $\mathrm{O}$ aumento das lâminas de irrigação proporcionou incremento significativo da maioria dos componentes da produção e da produtividade da cultura sem, no entanto, alterar o teor de óleo contido nas sementes. A aplicação da maior lâmina de água aumentou em $80 \%$ a produtividade em relação ao tratamento que não recebeu irrigação suplementar.
\end{abstract}

Palavras-chave: Ricinus communis L., componentes de produção, irrigação por gotejamento

\section{Yield of two castor bean cultivars under different depths of supplemental irrigation}

\begin{abstract}
This study evaluated the yield, components of production and oil content of two castor bean cultivars through drip irrigation with different water depths. The research was conducted in 2009 in an Oxisol clay in the experimental field in Dourados, Mato Grosso do Sul State. The experimental design was randomized blocks in factorial scheme with five water depths $(0,25,50,100$ and $150 \%$ of evapotranspiration for drip irrigation) in two castor bean cultivars (IAC 2028 and IAC 80) with four replications. The irrigation schedule was predetermined up to two irrigations per week except on rainy days. The increase of irrigation provided significant increase in most components of production and crop yield without changing the oil content of seeds. The application of higher water depth increased yield by $80 \%$ in relation to the treatment that received no supplemental irrigation.
\end{abstract}

Key words: Ricinus communis L., yield components, drip irrigation

\footnotetext{
1 Programas de Pós Graduação em Agronomia e em Engenharia Agrícola, Faculdade de Ciências Agrárias (FCA), Universidade Federal da Grande Dourados (UFGD), Rodovia Dourados-Itahum, Km 12, C.P. 533, CEP 79804-970, Dourados, MS. E-mail: guilhermebiscaro@ufgd.edu.br 2 Pós-Graduação em Estatística e Experimentação Agronômica, ESALQ/USP, CEP 13418-900. Piracicaba, SP. E-mail: brazvaz@usp.br FCA/UFGD, Dourados, MS. E-mail: graziane_giacon@hotmail.com; silvana-batista@live.com

${ }_{4}^{4}$ Programa de Pós Graduação em Engenharia Agrícola, FCA/UFGD, CEP 79825-070. Dourados, MS. E-mail: edergomes@ufgd.edu.br; anamarimotomiya@ufgd.edu.br; anamarimotomiya@ufgd.edu.br
} 


\section{INTRODUÇÃO}

A mamoneira (Ricinus communis L.), oleaginosa de relevante importância econômica e social, apresenta-se como alternativa para a produção do biodiesel (Souza et al., 2010). A cultura produz quantidade considerável de biomassa, suas folhas podem servir de alimento para o bicho da seda, as hastes contêm celulose para fabricação de papel e, das sementes, são obtidos o óleo e a torta, ricos em proteína (Cavalcanti et al., 2005).

Segundo estimativas da CONAB (2012), a área cultivada com mamona na safra 2011/12 deve ficar em 146,0 mil ha, com redução de $33,4 \%$ em referência à safra anterior. O cultivo se concentra na Bahia, cuja redução da área chegou a 49,6\%, cultivando apenas 71,0 mil ha ante os 140,8 mil ha da safra anterior. O Ceará também apresenta uma área expressiva, com 60 mil ha. A produtividade média da produção nacional de mamona prevista para a safra 2011/2012 deve ser de $521 \mathrm{~kg} \mathrm{ha}^{-1}$. A melhor média colhida encontra-se na região Sudeste, 1.021 $\mathrm{kg} \mathrm{ha}^{-1}$, mas as áreas são pequenas e estão diminuindo a cada safra.

A cultura se apresenta como alternativa de relevante importância econômica e social pois, em virtude das suas características, é capaz de produzir satisfatoriamente até sob condições de baixa precipitação pluvial; mesmo tendo sua produtividade afetada, tem-se mostrado resistente ao clima adverso quando se verificam perdas totais em outras culturas servindo, desta forma, como alternativa de trabalho e de renda, principalmente para o pequeno agricultor (Beltrão et al., 2005).

Segundo Barros Júnior et al. (2008) a mamoneira apresenta elevada eficiência na transformação da água consumida, com elevada produção de fitomassa na ausência de déficit hídrico. Para crescer, desenvolver e produzir satisfatoriamente, a mamoneira necessita de suprimento hídrico diferenciado nas suas fases fenológicas, o que requer manejo compatível com sua capacidade de retirada de água do solo (Freitas et al., 2010) Atualmente, pode-se utilizar a irrigação por gotejamento, que traz economia no uso da água e incremento da eficiência da irrigação. A mamoneira prefere solos bem drenados, sem impedimentos físicos, de textura média, porosos, profundos, de $\mathrm{pH}$ em torno de 6,5 e de boa fertilidade natural, com equilíbrio de nutrientes e sem ser salino nem alcalino, haja vista que a capacidade de suportar sais no ambiente edáfico é pequena, além de sua baixa capacidade de resistir à anoxia, ou mesmo à hipoxia, no meio edáfico (Weiss, 1983).

Objetivou-se, com este trabalho, avaliar o efeito de diferentes lâminas de água nos componentes de produção e a produtividade da cultura da mamona, irrigada por um sistema localizado por gotejamento, de acordo com as condições edafoclimáticas da região do Município de Dourados, MS.

\section{Material e MÉTOdos}

Este trabalho foi desenvolvido no ano agrícola de 2009, em uma área experimental localizada no município de Dourados, Estado do Mato Grosso do Sul, cujas coordenadas geográficas são $22^{\circ} 13^{\prime} 16^{\prime \prime} \mathrm{S}$ e $54^{\circ} 17^{\prime} 01^{\prime \prime} \mathrm{W}$, com altitude média de $452 \mathrm{~m}$.
O clima local é classificado como Cwa, segundo a classificação de Köppen.

O solo da área é classificado como Latossolo Vermelho distroférrico, textura muito argilosa, com as seguintes características: $\mathrm{pH}\left(\mathrm{CaCl}_{2}\right)=5,3 ; \mathrm{M} . \mathrm{O}=8,0 \mathrm{~g} \mathrm{~kg}^{-1} ; \mathrm{P}$-resina $=$ $5 \mathrm{mg} \mathrm{dm}{ }^{-3} ; \mathrm{K}^{+}=1,5 \mathrm{mmol} \mathrm{dm}^{-3} ; \mathrm{Ca}^{2+}=33,1 \mathrm{mmol} \mathrm{dm}{ }^{-3} ; \mathrm{Mg}^{2+}=$ $25,2 \mathrm{mmol}_{\mathrm{c}} \mathrm{dm}^{-3} ; \mathrm{H}^{+} \mathrm{Al}=55 \mathrm{mmol}_{\mathrm{c}}^{\mathrm{c}} \mathrm{dm}^{-3} ; \mathrm{CTC}=114,9 \mathrm{mmol}_{\mathrm{c}} \mathrm{dm}^{-3}$ $\mathrm{e} \mathrm{V}=52 \%$. Como cultura anterior, a soja foi colhida em $20 \mathrm{de}$ março de 2009, dois meses antes da semeadura da mamona. O preparo do solo foi realizado por uma aração e duas gradagens, 15 dias antes do plantio, sem aplicação de calcário.

O delineamento experimental foi em blocos casualizados (DBC) com dez tratamentos e quatro repetições; em cada parcela foram semeadas, manualmente, quatro linhas de mamona, cada uma contendo cinco plantas com espaçamento $1,0 \times 1,0 \mathrm{~m}$. Os tratamentos consistiram da aplicação de cinco lâminas de água $(0,25,50,100$ e $150 \%$ da evapotranspiração, para irrigação localizada - $\mathrm{ET}_{\mathrm{LOC}}$ ) em dois cultivares de mamona (IAC 2028 e IAC 80), com quatro repetições.

A semeadura foi realizada manualmente, no dia 12/05/2009, distribuindo-se três sementes por cova. As covas foram abertas utilizando-se apenas de uma haste do subsolador na linha de semeadura. A adubação foi realizada com $60 \mathrm{~kg} \mathrm{~N} \mathrm{ha}^{-1}$ (uréia), $90 \mathrm{~kg}$ de $\mathrm{P}_{2} \mathrm{O}_{5} \mathrm{ha}^{-1}$ (superfosfato simples) e $60 \mathrm{~kg} \mathrm{~K}_{2} \mathrm{O} \mathrm{ha}^{-1}$ (cloreto de potássio). As plantas daninhas foram controladas durante todo o experimento, por capina manual.

O sistema de irrigação foi do tipo localizado por gotejamento, com mangueiras gotejadoras de espessura de 200 microns e espaçamento de $30 \mathrm{~cm}$ entre emissores, sendo instalada uma mangueira gotejadora para cada linha da cultura. A vazão dos gotejadores foi determinada a campo para uma pressão de serviço constante de 8,4 m.c.a., sendo de $1,34 \mathrm{~L} \mathrm{~h}^{-1}$ gotejador $^{-1}$. A pressão de serviço do sistema de irrigação foi monitorada através de tomadas de pressão instaladas na tubulação de derivação para as linhas laterais de cada parcela.

O manejo da irrigação foi realizado com base na evapotranspiração da cultura e os tempos de irrigação calculados em uma planilha eletrônica utilizando-se um valor único de $\mathrm{Kc}(0,73)$, que representa a média dos valores de $\mathrm{Kc}$ nos diferentes estágios da cultur,a apresentados por Curi (2004), para a região de Santo Antônio do Leverge, MT, juntamente com as informações de evapotranspiração de referência fornecidas pela estação meteorológica automatizada pertencente à Universidade Federal da Grande Dourados.

O turno de rega adotado foi de quatro dias entre cada irrigação excetuando-se os períodos em que ocorriam precipitações, quando então era recalculado o momento exato da próxima irrigação. O controle do tempo de irrigação e da lâmina de água aplicada era realizado manualmente, através de registros individuais para cada tratamento. As lâminas totais de água aplicadas em cada tratamento no decorrer do experimento e a quantidade total de água recebida pelas plantas (lâmina + precipitação) estão apresentadas na Tabela 1 .

Durante o período do experimento ocorreram 64 precipitações, que totalizaram $736,1 \mathrm{~mm}$, dentre as quais foram realizadas 18 irrigações suplementares que foram suspensas a partir do dia 03/09 (Figura 1), quando a planta atingia o estado de maturação. Esta decisão de suspender a suplementação 
Tabela 1. Lâminas totais de água aplicadas em cada tratamento no decorrer do experimento

\begin{tabular}{crc}
\hline \multirow{2}{*}{ Tratamento } & Lâmina & Lâmina + precipitação \\
\cline { 2 - 3 } & \multicolumn{2}{c}{$\mathbf{( m m )}$} \\
0 & 0,00 & 736,10 \\
$25 \%$ da ET & 27,00 & 763,10 \\
$50 \%$ da $\mathrm{ET}_{\text {LOC }}$ & 54,00 & 790,10 \\
$100 \%$ da $\mathrm{ET}_{\text {LOC }}$ & 108,00 & 844,10 \\
$150 \%$ da $\mathrm{ET}_{\text {LOC }}$ & 162,00 & 898,10 \\
\hline
\end{tabular}

$\mathrm{ET}_{\text {Loc }}$ - evapotranspiração para irrigação localizada

hídrica foi adotada com base no que foi observado por Souza et al. (2007) onde observaram, estudando épocas de plantio e manejo da irrigação para a mamona, que a suplementação hídrica nos estádios mais avançados da cultura não é uma prática vantajosa.

Antes da implantação deste trabalho realizou-se um ensaio de determinação da área molhada pelos gotejadores na área experimental, utilizando-se a seguinte metodologia, baseada no princípio do vaso de Mariotte: inserem-se canudos plásticos (semelhantes aos utilizados em balões de festa) na tampa de garrafas PET de 2 L e na sua parte inferior são instalados gotejadores de vazão regulável.

Ao encher as garrafas com água e fechar a tampa, a água que sairá pelo gotejador não sofrerá influência da coluna d'água, mesmo diminuindo com o tempo. Ao se regular a vazão do gotejador ela permanecerá constante e isenta de oscilações. A instalação das garrafas PET na área experimental foi realizada da seguinte maneira: foram escolhidos pontos representativos da área repetindo-se a determinação três vezes em cada ponto; as garrafas foram instaladas com espaçamento de dois metros entre cada ponto de medição do bulbo molhado; as determinações do bulbo foram feitas em quatro leituras, divididas em intervalos de tempo predeterminados: $1^{\mathrm{a}}$ leitura após 1 h, $2^{\mathrm{a}}$ leitura após 2 h, $3^{\mathrm{a}}$ leitura após $3 \mathrm{~h}$ e $4^{\mathrm{a}}$ leitura após $4 \mathrm{~h}$ de ensaio.

Depois de realizadas as leituras de campo, os valores foram plotados em um gráfico, determinando-se a largura e a profundidade do bulbo molhado de acordo com o tempo de irrigação. Segundo Maia et al. (2010), a utilização de um modelo potencial é a mais adequada para estimar a profundidade e o diâmetro do bulbo em vários tipos de solo. Ao se obter a equação do modelo, estimaram-se as dimensões do bulbo para vários tempos de irrigação. Após determinar a área molhada do gotejador e a porcentagem molhada foram calculados o valor do coeficiente de ajuste e a evapotranspiração para irrigação localizada $\left(\mathrm{ET}_{\text {LoC }}\right)$ que, neste experimento correspondeu a $65 \%$ da evapotranspiração da cultura $\left(\mathrm{ET}_{\mathrm{C}}\right)$.

No dia 30/10/2009 realizou-se, de uma única vez, a colheita da cultura, quando todos os cachos da planta atingiram a maturidade fisiológica; sua realização foi manual e individualmente, por parcela, considerando-se área útil as duas linhas centrais de cada parcela desprezando-se também $0,5 \mathrm{~m}$ nas extremidades de cada linha, após o que o material foi secado à sombra e limpo para realização da debulha manual. Foram realizadas as seguintes avaliações: número de racemos por planta, número de frutos por racemo, número de frutos por planta, número de sementes por planta, massa de 1000 sementes, número de sementes por hectare e a produtividade da cultura.

Obteve-se a massa de 1000 sementes depois delas passarem por um processo de secagem natural, ficando depois acondicionadas em sacos de papel permeável, em local seco, fresco e protegido de variações abruptas de umidade e temperatura, dentro do Laboratório de Irrigação e Qualidade da Água da FCA/UFGD. O tempo de armazenagem foi de 6 meses; depois deste período foi obtida a massa das sementes

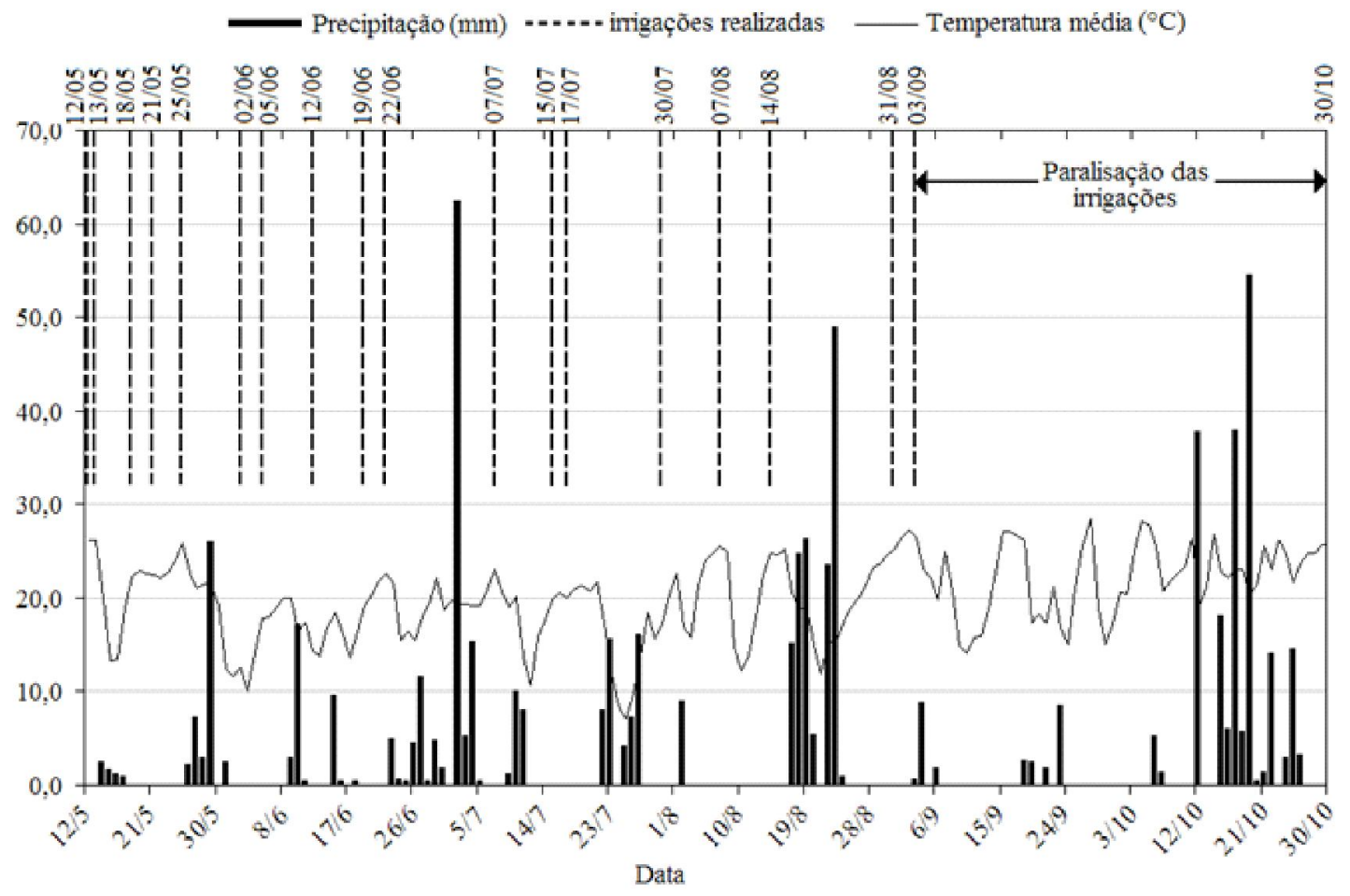

Figura 1. Temperaturas médias, precipitação e irrigações realizadas no decorrer do experimento 
(1000 sementes por parcela) e, posteriormente, determinada a produtividade da cultura, cujos grãos tinham umidade média de $10 \%$.

As análises de lipídeo (\% base seca) foram realizadas através de extração direta em Soxhlet utilizando-se o hexano, que é o solvente orgânico muito utilizado no processo de extração, por ser o mais seletivo, possuir estreita faixa de ebulição e ser imiscível com a águ, o que evita misturas azeotrópicas. A determinação do teor de óleo nas sementes foi realizada em três repetições, com base nos procedimentos definidos pela IUPAC (Paquot, 1979). O aparelho utilizado foi extrator Soxhlet Marconi ma 491/06.

A avaliação estatística do experimento foi realizada através de programa computacional sendo que os dados foram submetidos às análises de variância e regressão, a 1 e 5\% de probabilidade.

\section{RESULTADOS E DISCUSSÃO}

Durante o período experimental a temperatura média foi de $20{ }^{\circ} \mathrm{C}$ e a umidade relativa média, de $73,3 \%$. A precipitação acumulada foi de $736,1 \mathrm{~mm}$, sendo que a precipitação total mensal foi aumentando no decorrer do experimento (Figura 2), o que dificultou o manejo das lâminas de irrigação e fez com que mesmo as menores lâminas pudessem apresentar resultados positivos.

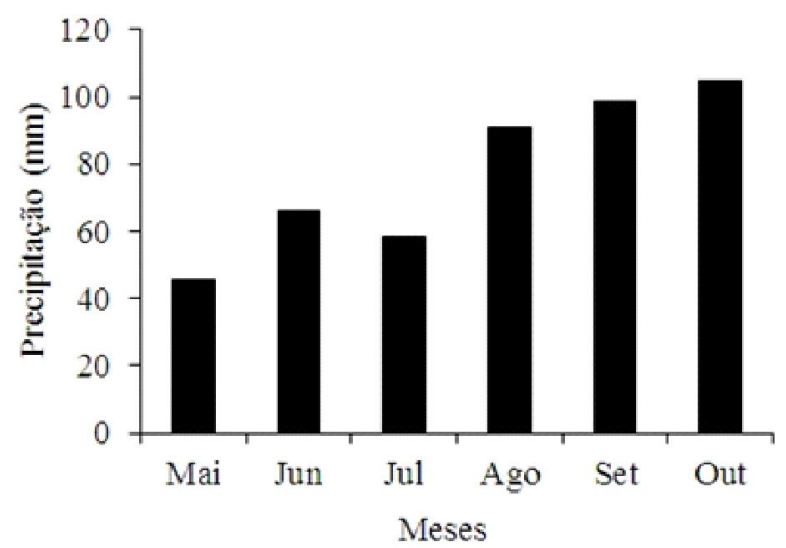

Figura 2. Precipitações totais mensais ocorridas no durante experimento
De acordo com a Tabela 2, as lâminas suplementares de irrigação apresentaram efeitos significativos pelo teste $\mathrm{F}(\mathrm{P}<$ $0,01)$ nos componentes número de racemos por planta (NRPP), número de frutos por planta (NFPP), número de sementes por planta (NSPP), número de sementes por hectare (NSPH) e produtividade por hectare (PROD), para as duas cultivares estudadas (IAC 2028 e IAC 80). Efeito significativo pelo teste $\mathrm{F}(\mathrm{P}<0,05)$ foi observado entre as cultivares mas apenas em relação ao número de racemos por planta. Não houve interação significativa entre as lâminas aplicadas e as cultivares estudadas.

Observa-se, na Figura 3A, que houve resposta quadrática significativa $(\mathrm{P}<0,01)$ em função da lâmina de água aplicada nas duas cultivares, para o número de racemos por planta no momento da colheita obtendo-se 6,15 e 5,6 racemos por planta, para IAC 80 e IAC 2028, respectivamente, ambas com a lâmina de $150 \%$ da evapotranspiração para irrigação localizada $\left(\mathrm{ET}_{\text {LOC }}\right)$. Verificou-se que a quantidade de água aplicada, mesmo de forma suplementar, foi determinante para aumentar o número de racemos em cada planta de mamona.

Rodrigues et al. (2002) verificaram, trabalhando com a cultivar BRS Paraguaçu, aumento significativo do comprimento do racemo, número de frutos e massa de 100 sementes com o incremento do nível de irrigação. Na mesma linha de pesquisa Souza et al. (2007) constataram, ao trabalhar com a cultivar Mirante 10, aumento de $148 \%$ no número médio de racemos por planta quando da irrigação de suplementação comparada à de sequeiro. Ainda segundo os autores, os racemos com menor número de frutos, menor comprimento e menor produção de grãos por planta, foram registrados no cultivo de sequeiro.

O número de frutos por racemo não apresentou resposta significativa com a variação da quantidade de água aplicada nem, tampouco houve diferença significativa entre as duas variedades observando-se as médias de 25,3 frutos por racemo para a cultivar IAC 2028 e 22,2 frutos por racemos para a cultivar IAC 80. Freitas et al. (2010) observaram, entretanto, estudando o comportamento de cultivares de mamona em diferentes níveis de irrigação por gotejamento, um aumento linear para a IAC Guarani e quadrático para a BRS Paraguaçu, no número de frutos por racemo. O aumento dessas variáveis de produção com o favorecimento hídrico, corrobora com Souza et al. (2007) ao constatarem que a irrigação favoreceu o aumento do comprimento dos racemos e do número de frutos por racemo.

Tabela 2. Análise de variância dos dados referentes ao número de racemos por planta (NRPP), número de frutos por racemo (NFPR), número de frutos por planta (NFPP), número de sementes por planta (NSPP), número de sementes por hectare (NSPH), massa de 1000 sementes (M1000) e produtividade por hectare (PROD) de sementes de mamona, em função de diferentes lâminas de irrigação

\begin{tabular}{|c|c|c|c|c|c|c|c|c|}
\hline \multirow{2}{*}{ FV } & \multirow{2}{*}{ GL } & \multicolumn{7}{|c|}{ Quadrado médio } \\
\hline & & NRPP & NFPR & NFPP & NSPP & NSPH & M1000 & PROD \\
\hline Lâmina & 4 & $9,09 * *$ & $2,610^{\text {ns }}$ & $3664,46^{\star \star}$ & $35435,24^{\star \star}$ & $3,54 \mathrm{e}+0012^{\star \star}$ & $374,70^{\text {ns }}$ & $535892,57^{* *}$ \\
\hline Cultivar & 1 & 3,60 * & $96,100^{\text {ns }}$ & $54,76^{\mathrm{ns}}$ & $1034,29^{\text {ns }}$ & $1,03 \mathrm{e}+0011^{\mathrm{ns}}$ & $1447,09^{\text {ns }}$ & $65492,60^{\text {ns }}$ \\
\hline Bloco & 3 & $1,801^{\text {ns }}$ & $11,130^{\text {ns }}$ & $1500,32^{\star \star}$ & $11472,73^{\star}$ & $1,15 e+0012^{\star}$ & $402,34^{\text {ns }}$ & $200441,85^{\text {ns }}$ \\
\hline Interação L*C & 4 & $0,46^{\mathrm{ns}}$ & $0,642^{\text {ns }}$ & $77,41^{\text {ns }}$ & $401,88^{\text {ns }}$ & $4,02 \mathrm{e}+0010^{\mathrm{ns}}$ & $125,41^{\text {ns }}$ & $5125,84^{\text {ns }}$ \\
\hline Resíduo & 27 & 0,80 & 23,42 & 305,82 & 2797,72 & $2,798 e+0011$ & 525,75 & 53379,63 \\
\hline CV (\%) & & 19,06 & 20,34 & 16,37 & 16,42 & 16,42 & 6,27 & 19,50 \\
\hline Média geral & & 4,68 & 23,79 & 106,82 & 322,04 & 3220350,00 & 365,69 & 1184,69 \\
\hline
\end{tabular}

** significativo a 0,01 de probabilidade pelo teste $\mathrm{F}$; ${ }^{2}$ significativo a 0,05 de probabilidade pelo teste $\mathrm{F}$; ${ }^{\text {ns }}$ não significativo; $\mathrm{FV}$ - fonte de variação 

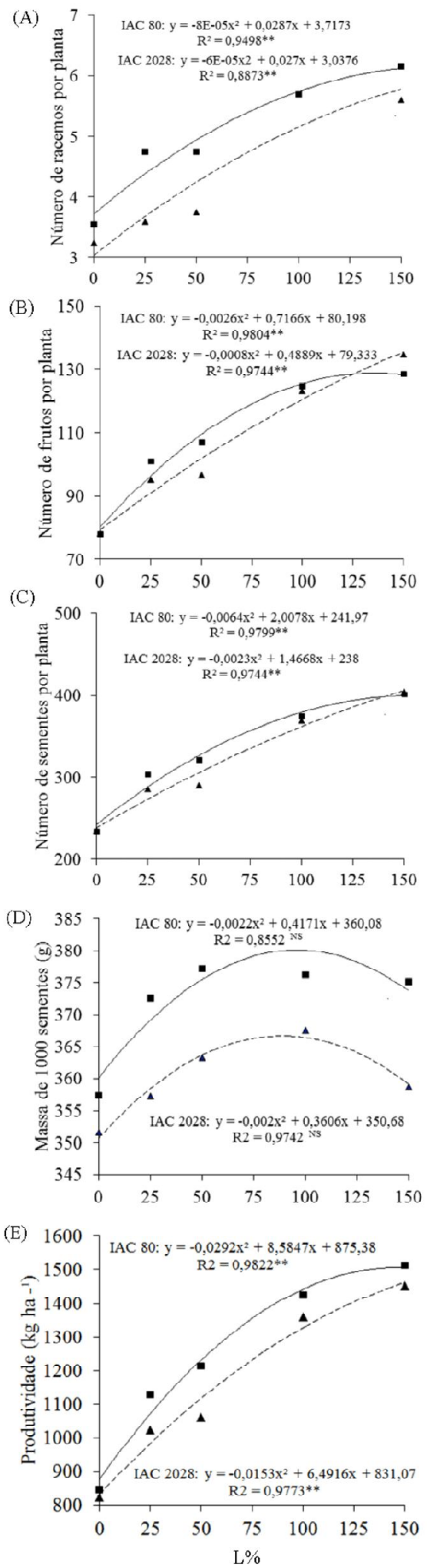

L\%= Laminina de água correspondente a urna porcentagern da evapotranspiração para irrigaçăo localizada (ETloc)

A Cultivar de mamona IAC 2028

- Cultivar de mamona LAC 80

** significativo a $1 \%$ de probabilidade pelo teste $\mathrm{F}$. NS não significativo pelo teste $\mathrm{F}$

Figura 3. Número de racemos por planta $(A)$; número de frutos por planta (B); número de sementes por planta (C); massa de mil sementes (D); produtividade de sementes $\left(\mathrm{kg} \mathrm{ha}^{-1}\right)(\mathrm{E})$ nas cultivares IAC 80 e IAC 2028 em função das lâminas de irrigação. Dourados, MS, 2010
Em relação ao número de frutos por planta (Figura 3B), as lâminas de irrigação proporcionaram resposta significativa ( $\mathrm{P}$ $<0,01)$ nas duas cultivares estudadas observando-se, na maior lâmina ( $150 \%$ da $\left.\mathrm{ET}_{\mathrm{LOC}}\right) 128,8$ e 134,8 frutos por planta para as cultivares IAC 80 e IAC 2028, respectivamente, não havendo diferença significativa entre ambas.

$\mathrm{O}$ número de sementes por planta (Figura $3 \mathrm{C}$ ) também apresentou resposta quadrática significativa $(P<0,01) \mathrm{em}$ função da lâmina de água aplicada não apresentando, entretanto, diferença significativa entre as duas variedades.

A massa de 1000 sementes (Figura 3D) não apresentou respostas significativas em relação às lâminas aplicadas e, muito menos, entre as cultivares estudadas, apesar de apresentar, em ambas, comportamento quadrático, sendo os maiores valores para as lâminas estimadas de 95 e $90 \%$ nas cultivares IAC 80 e IAC 2028, respectivamente.

Koutrobas et al. (2000) constataram aumento da massa de cem sementes com o uso da irrigação de suplementação; no entanto, segundo os autores, a disponibilidade hídrica exerce pouca influência nesta característica produtiva. Moreira et al. (2009) verificaram, estudando os efeitos de diferentes lâminas de irrigação na produtividade da mamoneira variedade IAC Guarani, ao contrário deste trabalho, que as lâminas de irrigação influenciaram o peso de 100 sementes (P100SR), para os racemos de três ordens analisadas, a nível de 5\% de probabilidade, pelo teste $\mathrm{F}$.

Rodrigues et al. (2002) constataram aumento significativo do comprimento do racemo, número de frutos e massa de 100 sementes com o incremento do nível de irrigação na cultivar BRS Paraguaçu. A aplicação de maiores lâminas de água na cultura da mamona eleva o potencial de água na planta e nas folhas, favorecendo a abertura dos estômatos, facilitando o fluxo de $\mathrm{CO}_{2}$ e interferindo no acúmulo de fotoassimilados o que, possivelmente, acarreta no aumento da produção de tecidos e no tamanho das sementes aumentando, assim, sua massa.

Observa-se, na Figura 3E, uma resposta quadrática significativa $(\mathrm{P}<0,01)$ em função da lâmina de água aplicada nas duas cultivares para a produtividade $\mathrm{em} \mathrm{kg} \mathrm{ha-1}$, obtendo-se 1513,9 e $1452,4 \mathrm{~kg}$ de semente por hectare, para IAC 80 e IAC 2028, respectivamente, ambas com a lâmina de $150 \%$ da evapotranspiração para irrigação localizada $\left(\mathrm{ET}_{\mathrm{LOC}}\right)$. Verificou-se que a quantidade de água aplicada, mesmo de forma suplementar, foi importante para aumentar a produtividade da cultura.

Tomando-se por base a produtividade média de algumas cultivares do Instituto Agronômico de Campinas (IAC), que variam entre 1.500 a $2.000 \mathrm{~kg} \mathrm{ha}^{-1}$, observa-se que neste experimento as produtividades máximas estimadas (1513,9e 1452,4 quilos de semente por hectare, para IAC 80 e IAC 2028) mesmo não realizando nenhuma adubação de cobertura, ficaram próximas à faixa prevista para o Estado de São Paulo.

Segundo Souza et al. (2007) após a estação chuvosa ou durante a ocorrência de veranicos a suplementação hídrica pode contribuir para o aumento da produtividade uma vez que, por se tratar de uma planta de crescimento indeterminado, continuará a florescer e a produzir. Os mesmos autores notaram, estudando épocas de plantio e manejo da irrigação para a mamoneira cultivar BRS Nordestina, que não ocorreu diferença estatística entre as produtividades de grãos nos plantios de dezembro de 2003 e fevereiro e março de 2004, cujos valores se situaram entre 1.774 e $2.634 \mathrm{~kg} \mathrm{ha}^{-1}$, produtividades essas superiores, portanto, às 
mencionadas na literatura para a cultivar BRS Nordestina em condições de sequeiro, ou seja, de $1.500 \mathrm{~kg} \mathrm{ha}^{-1}$.

Segundo Beltrão et al. (2005), na maturação dos frutos e na colheita são requeridos períodos secos. Na prática, porém, isto nem sempre ocorre e as irregularidades climáticas provocam redução de produtividade. Irrigando a mamoneira cv. BRS Energia, Silva et al. (2009) obtiveram uma produtividade total de $1.317,09 \mathrm{~kg} \mathrm{ha}^{-1}$ para a lâmina aplicada de 487,5 mm. Amamona pode atingir rendimento superior a $1500 \mathrm{~kg} \mathrm{ha}^{-1} \mathrm{em}$ zonas com precipitação pluvial acumulada, maior que $700 \mathrm{~mm}$ (Weiss, 1983). Savy Filho et al. (2007) estudaram a cultivar IAC-2028, avaliada em relação à produtividade de grãos, em três locais do estado de São Paulo (Adamantina, Pindorama e Campinas) e em quatro safras agrícolas: 1999/2000, 2002/2003, 2003/2004 e 2006. A produtividade média foi de $1.950 \mathrm{~kg} \mathrm{ha}^{-1}$.

Observou-se, nas condições deste experimento, que a quantidade de água aplicada não interferiu significativamente no teor de óleo das sementes de mamona, observando-se um teor médio de óleo de 34,6\%. Segundo Conceição et al. (2007), o óleo da mamona é um triglicerídeo derivado do ácido ricinoléico o qual se constitui de $90 \%$ de ácidos graxos presentes na molécula e de $10 \%$ de ácidos graxos não hidroxiláveis, principalmente por ácidos oléicos e linoléicos. Como a produtividade foi influenciada significativamente pela quantidade de água aplicada na cultura, as maiores lâminas de água propostas neste trabalho, também proporcionaram a maior quantidade de óleo por hectare (523,8 e 502,5 kg de óleo por hectare, para IAC 80 e IAC 2028).

\section{ConClusõES}

1. O aumento das lâminas de irrigação proporcionou incremento significativo da maioria dos componentes da produção e da produtividade da cultura, sem alterar o teor de óleo contido nas sementes.

2. A cultivar IAC 80 apresentou maior quantidade de racemos por planta do que a cultivar IAC 2028, em todas as lâminas de irrigação aplicadas.

3. A aplicação da lâmina de água baseada em $150 \%$ da evapotranspiração localizada aumentou em $80 \%$ a produtividade em relação ao tratamento que não recebeu irrigação suplementar.

\section{AgradeCimentos}

À Fundação de Apoio ao Desenvolvimento do Ensino, Ciência e Tecnologia do Estado de Mato Grosso do Sul, FUNDECT, pelo apoio financeiro e aos acadêmicos colaboradores do Grupo de Estudos em Irrigação - GEIR.

\section{LITERATURA CITADA}

Barros Júnior, G.; Guerra, H. O. C.; Cavalcanti, M. L. F.; Lacerda, R. D. de. Consumo de água e eficiência do uso para duas cultivares de mamona submetidas a estresse hídrico. Revista Brasileira de Engenharia Agrícola e Ambiental, v.12, p.350$355,2008$.
Beltrão, N. E. de M.; Cartaxo, W. V.; Pereira, S. R. P.; Soares, J. J.; Silva, O. R. R. F. O cultivo sustentável da mamona no Semi-árido Brasileiro. Campina Grande: Embrapa CNPA, 2005. 23p. Circular Técnica, 84

Cavalcanti, M. L. F.; Fernandes, P. D. ; Gheyi, H. R.; Barros Júnior, G.; Soares, F. A. L. Siqueira, E. da C. Tolerância da mamoneira BRS 149 à salinidade: Germinação e características de crescimento. Revista Brasileira de Engenharia Agrícola e Ambiental, v.9 (suplemento), p.57-61, 2005.

CONAB - Companhia Nacional de Abastecimento. Acompanhamento de safra brasileira: grãos, sétimo levantamento, abril 2012. Brasília: CONAB, 2012,37p.

Conceição, M. M.; Roberlúcia, A. C.; Silva, F. C.; Bezerra, A. F.; Fernandes, V. F. Thermoanalytical characterization of castor oil biodiesel. Renewable \& Sustainable Energy Reviews, v.11, p.964-975, 2007.

Curi, S. Evapotranspiração e coeficientes de cultura da mamoneira (Ricinus communis L.) em Santo Antônio do Leverger-MT. In: Congresso Brasileiro de Mamona, 1,2004, Campina Grande. Anais...Campina Grande: Embrapa Algodão, 2004. CD-Rom

Freitas, C. A. S. de, Bezerra, F. M. L.; Silva, A. R. A. da; Pereira Filho, J. V.; Feitosa, D. R. C. Comportamento de cultivares de mamona em níveis de irrigação por gotejamento em Pentecoste, CE. Revista Brasileira de Engenharia Agrícola e Ambiental, v.14, p.1059-1066, 2010.

Koutroubas, S. D.; Papakosta, D. K.; Doitsinis, A. Water requirements for castor oil crop (Ricinus communis $\mathrm{L}$.) in a Mediterranean climate. Journal of Agronomy \& Crop Science, v.184, p.33-41, 2000.

Maia, C. E.; Levien, S. L. A; Medeiros, J. F. de; Dantas Neto, J. Dimensões de bulbo molhado na irrigação por gotejamento superficial. Revista Ciência Agronômica, v.41, p.149-158, 2010.

Moreira, L. G.; Viana, T. V. de A.; Marinho, A. B.; Nobre, J. G. A.; Lima, A. D.; Albuquerque, A. H. P. Efeito de diferentes lâminas de irrigação na produtividade da mamoneira variedade IAC Guarani. Revista Brasileira de Ciências Agrárias, v.4, p.449-455, 2009.

Paquot, C. Standard methods for the analysis of oils, fats and derivatives. 6.ed. Oxford: Pergamon Press, 1979. 170p.

Rodrigues, R. F. de O.; Oliveira, F. de; Fonseca, A. M. As folhas de palma Christi - Ricinus communis L. Euphorbiaceae Jussieu. Revisão de conhecimentos. Revista Lacta, v.20, p.183-194, 2002.

Savy Filho, A.; Amorim, E. P.; Ramos, N. P.; Martins, A. L.M.; Cavichioli, J. C. IAC-2028: Nova cultivar de mamona. Pesquisa Agropecuária Brasileira, v.42, p.449-452, 2007.

Silva, S. M. S.; Gheyi, H. R.; Beltrão, N. E. de M.; Santos, J. W. dos; Soares, F. A. L. Dotações hídricas em densidades de plantas na cultura da mamoneira cv. BRS Energia. Revista Brasileira de Ciências Agrárias, v.4, p.338-348, 2009.

Souza, A. dos S.; Távora, F. J. A.; Pitombeira, J. B.; Bezerra, F. M. L. Épocas de plantio e manejo da irrigação para a mamoneira. II - Crescimento e produtividade. Revista Ciência Agronômica, v.38, p.422-429, 2007.

Souza, N. C.; Mota, S. B.; Bezerra, F. M. L.; Aquino, B. F.; Santos, A. B. Produtividade da mamona irrigada com esgoto doméstico tratado. Revista Brasileira de Engenharia Agrícola e Ambiental, v.14, p.478-484, 2010.

Weiss, E. A. Oil seed crops. London: Longman, 1983. 659p. 